\title{
Corpo e psicologia: uma revisão da produção científica brasileira na primeira década dos anos 2000
}

Body and psychology: a review of the Brazilian scientific production in the first decade of the 2000s

Cuerpo y psicología: una revisión de la producción científica brasileña en la primera década de los años 2000

\author{
Joanneliese de Lucas Freitas ${ }^{*}$ \\ Caroline Bevilacqua* \\ Juliana Carolina de Castilhos ${ }^{* *}$ \\ Luis Henrique Fuck Michel ${ }^{* * * *}$
}

Caroline Pértile

\begin{abstract}
Resumo
Este estudo teve como objetivo mapear as publicações científicas sobre corpo na Psicologia brasileira na última década. Foram selecionados 126 artigos nas bases de dados Pepsic e Scielo, buscados com os descritores "corpo" e "corporeidade", publicados entre 2000 e 2009, em português. Os artigos foram agrupados em categorias de análise, assim distribuídas: (1) cita ou problematiza "corpo" ou "corporeidade"; (2) áreas de estudo; (3) teorias de base; (4) metodologia; e (5) concepçóes de corpo. Nota-se que a década foi marcada por um forte crescimento de publicaçóes. A área que mais publicou sobre o tema foi a "clínica", e a teoria, a "psicanálise". Os estudos teóricos predominam sobre os empíricos e há uma incidência relevante de estudos multidisciplinares. O tema emerge como complexo, fortemente problematizado pela Psicologia. As análises também apontam para uma dispersão conceitual do problema e uma necessidade de avanço nos estudos empíricos.
\end{abstract}

Palavras-chave: Corpo. Corporeidade. Paradigma. Psicologia.

\footnotetext{
Texto recebido em novembro de 2012 e aprovado para publicação em agosto de 2014.

"Psicóloga, mestre e doutora em Psicologia pela Universidade de Brasília (UnB) e docente do curso de graduação em Psicologia da Universidade Federal do Paraná (UFPR). Pesquisadora do Laboratório de Psicopatologia Fundamental e membro do grupo de pesquisa CNPq Fundamentos fenomenológicos-existenciais de diferentes práticas em psicologia (UERJ). Endereço: Praça Santos Andrade, 50, sala 215, Ala Alfredo Buffren - Centro, Curitiba-PR. CEP: 80060-240. E-mail: joanne@globo.com.

"Psicóloga graduada pela Universidade Federal do Paraná (UFPR). Endereço: Praça Santos Andrade, 50, sala 215, Ala Alfredo Buffren - Centro, Curitiba-PR. CEP: 80060-240.E-mail: carol53@gmail.com.

*** Graduanda em Psicologia pela Universidade Federal do Paraná (UFPR);Endereço: Praça Santos Andrade, 50, sala 215, Ala Alfredo Buffren - Centro, Curitiba-PR. CEP: 80060-240. E-mail: juhlianah@gmail.com.

${ }^{* * * *}$ Graduado em Psicologia pela Universidade Federal do Paraná (UFPR) e Mestrando em Psicologia Clínica pela mesma universidade com bolsa CAPES. Endereço: Praça Santos Andrade, 50, sala 215, Ala Alfredo Buffren - Centro, Curitiba-PR. CEP: 80060-240. E-mail: luis.hfmichel@gmail.com.

${ }^{* * * * *}$ Psicóloga graduada pela Universidade Federal do Paraná (UFPR). Endereço: Praça Santos Andrade, 50, sala 215, Ala Alfredo Buffren - Centro, Curitiba-PR. CEP: 80060-240.
} 


\begin{abstract}
This study aims to construct an overview of the scientific literature about the body in Brazilian Psychology during the last decade. One hundred and twenty-six articles were selected from the databases Pepsic and Scielo searched with the descriptors "body" and "embodiment" published between 2000 and 2009, in Portuguese. These articles were grouped into five groups for analysis, as follows: (1) only mentions or discusses "body" or "embodiment", (2) study areas, (3) basic theories, (4) methodology, and (5) conceptions of the body. One can notice that the decade was marked by a strong growth in publications. The area that has published the most was "clinic" and the theory was the "psychoanalysis". Theoretical studies predominate over empirical and there is a significant incidence of multidisciplinary studies. The issue arises as a complex, strongly questioned by Psychology. The analysis also points to a conceptual dispersion of the problem and a need to move on empirical studies.
\end{abstract}

Keywords: Body. Corporeality. Paradigm. Psychology.

\title{
Resumen
}

Este estudio tuvo como objetivo describir la literatura científica sobre el cuerpo en la psicología brasileña en la última década. Fueron seleccionados 126 artículos en las bases de datos Pepsic y Scielo, buscados con los descriptores "cuerpo" y "corporalidad", publicados entre 2000 y 2009 en portugués. Los artículos fueron agrupados en categorías de análisis de la siguiente manera: (1) cita o problematiza "cuerpo" o "corporeidad", (2) áreas de estudio, (3) teorías de base, (4) metodología y (5) concepciones sobre el cuerpo. Se nota que la década fue marcada por un fuerte crecimiento en las publicaciones. El área que más publicó sobre el tema es el área "clínica" y la teoría, el "psicoanálisis". Los estudios teóricos predominan sobre los empíricos y hay una incidencia significativa de estudios multidisciplinares. El tema surge como complejo y fuertemente cuestionado por la Psicología. Los análisis también apuntan a una dispersión conceptual del problema y una necesidad de avanzar en los estudios empíricos.

Palabras clave: Cuerpo. Corporeidad. Paradigma. Psicología. 
$\mathrm{H}$ á, em nossa cultura, uma crescente hipervalorização do corpo e de suas imagens. Vivemos a época da imposição da fotogenia, quando a beleza se circunscreve cada vez mais por meio dos avanços tecnológicos e suas intervençôes, seja por uma busca desenfreada da juventude, seja por uma questão estética ou artística. $\mathrm{O}$ corpo tem se tornado tema relevante e central em diversas áreas, tais como a Antropologia e a Filosofia, além de ser um problema central para a própria Psicologia (Xavier, 2008), tendo surgido no centro da discussão sobre as relações entre a fisiologia e os atos psíquicos que dominavam o zeitgeist da época. A centralidade que o debate ainda ocupa em nossos dias nos convida à reflexão especialmente sobre qual a contribuição oferecida pela Psicologia para se pensarem o problema mente e corpo e a questão da corporeidade. Herdaríamos as reflexões antropológicas do corpo como construção social? Ou estaríamos marcados pelos avanços das neurociências?

Especialmente diante do avanço das neurociências por um lado e das políticas queer por outro, responsáveis por importantes mudanças nas práticas de saúde, tal como vemos, por exemplo, na inclusão das cirurgias de mudança de sexo realizadas pelo SUS, o debate mente e corpo retorna como capital. Por vezes centrado nos problemas psiquismo-corpo, mente-cérebro, ou mesmo desde uma reflexão centrada na perda do corpo, ou no "corpo sem órgãos" da esquizoanálise, tal debate marca definitivamente novas fronteiras na compreensão das relaçôes entre a natureza e a cultura (Ribeiro, 2003).

Os conceitos de corpo e de mente mudam ao longo da história e são extremamente significativos para a Psicologia tanto pelas implicaçôes para o delineamento de seu objeto de estudo quanto pelas implicaçôes para a compreensão de problemas fundamentais, como saúde e doença (Sant'Anna, 2004; Silva, 2004). Na atualidade, multiplicam-se as proposições teóricas sobre as relações mente-corpo: dualismos, monismos idealistas e concepções neurocêntricas (Xavier, 2008). Entretanto a questão do corpo e da corporeidade tem sido, de forma significativa, excluída da Psicologia (Goia, 2007); segundo o autor, à exceção das perspectivas da terapia corporal, mesmo se considerarmos a psicossomática, em que o corpo surge como um reflexo da psique. Pruzinsky e Cash (2002), diversamente, não afirmam que as leituras e teorizaçôes sobre as temáticas se limitariam àquelas das abordagens clínicas corporais; diversamente, afirmam que a questão do corpo tem sido estudada frequentemente sob uma perspectiva mecanicista e dualista, em que mente é, em geral, compreendida como oposta à corporeidade, inclusive em sua natureza, tal como se nota nas teorias representacionistas sobre o corpo, ou nas teorias sobre imagem corporal. 
A clássica representação cartesiana do corpo como uma máquina tem tradicionalmente sido reproduzida, quando não na concepção teórica, nas práticas que permeiam o fazer do psicólogo, inclusive no que diz respeito aos métodos aplicados ao seu estudo. Essa aparente dicotomia se concretiza com a valorização de um dos polos (corpo ou mente) em detrimento do outro. Diante desse contexto, os estudos sobre as questôes que envolvem a corporeidade começam paulatinamente a chamar a atenção da comunidade científica em Psicologia, especialmente nas áreas de clínica, saúde e desenvolvimento (Scorsolini-Comin \& Amorim, 2008).

Constatando a necessidade de se compreenderem os parâmetros pelos quais atualmente se discute o problema do corpo na Psicologia e a necessidade de ampliar e aprofundar o reconhecimento do "corpo vivido" como participante dos fenômenos psíquicos, ou seja, de a Psicologia alargar seu espaço de diálogo com um paradigma diverso da usual concepção dualista, decidimos realizar uma revisão da literatura sobre corpo e corporeidade na área. Ao mesmo tempo, interessou-nos investigar se os autores que trabalham com o tema têm problematizado a questão do corpo em Psicologia, a ponto de formular conceituações de corpo e corporeidade, bem como quais são as diferentes concepções utilizadas. Escolhemos a primeira década do século XXI pela sua relevância na proliferação de publicações e de novos paradigmas sobre o corpo em outras áreas que não a Psicologia.

O único estudo desse porte em Psicologia é o de Scorsolini-Comin e Amorim (2008). Os autores, ao analisarem o desenvolvimento de crianças com paralisia cerebral em inclusão, tiveram a necessidade de destacar o papel do corpo nesse processo. Realizaram, então, uma extensa revisão bibliográfica nas bases de dados PsycInfo, Medline, Scielo e Lilacs, selecionando artigos publicados de 1970 a 2005 nas línguas inglesa, portuguesa e espanhola. Perceberam que a questão do corpo tem sido bastante negligenciada pelos estudos em Psicologia e que ela "representa tema controverso na história da humanidade, com diversos enfoques, conforme o período histórico, além dos aspectos discursivo-culturais de um mesmo período histórico e/ou grupo social" (Scorsolini-Comin \& Amorim, 2008, p. 194). Esses autores encontraram também um grande número de pesquisas fundamentadas no modo biologizante de abordar corporeidade, herança do modelo médico. Verificaram, ao mesmo tempo, o quanto é atual a discussão sobre corporeidade, uma vez que o número de publicações aumentou a partir da década de 1990 e, mais ainda, na primeira metade da década de 2000. Constatou-se "um ponto comum entre a maioria dos diversos artigos: a busca dos autores por romper com as dicotomias clássicas na ciência" (Scorsolini-Comin $\&$ Amorim, 2008, p. 203). Chamou a atenção dos autores o destaque dado na 
literatura às concepções fenomenológicas de Merleau-Ponty bem como o fato de apenas um texto ter definido e conceituado corporeidade, enquanto os demais apenas dialogaram com o termo. Entre suas conclusões, os autores afirmam que "mesmo com a atualidade da questão, acredita-se que os estudos existentes ainda são escassos, notadamente na área da Psicologia" (Scorsolini-Comin \& Amorim, 2008, p. 212).

Esta pesquisa teve como objetivo estudar a forma como o corpo tem sido pesquisado, conceituado e compreendido pela Psicologia no Brasil, especialmente na última década (primeira década do século XXI). A partir disso, pretendemos mapear como a Psicologia brasileira tem estudado as questóes do corpo e da corporeidade e se os estudos sobre o tema têm crescido ou não, como tais estudos têm sido realizados e como se compreendem tais conceitos, por meio das publicaçôes científicas no período citado. Há indicadores na literatura de que a questão do corpo tem crescido como tema de interesse na Psicologia, apesar de carecer de melhor compreensão e definição do ponto de vista psicológico (Scorsolini-Comin \& Amorim, 2008). Tal estudo de mapeamento permite ampliar a compreensão sobre o estado da arte, assim como tornar visível quais são os enfoques dados por certa área em um determinado tema, suas tendências de estudo e suas lacunas.

\section{Método}

A metodologia de coleta de dados adotada foi a revisão bibliográfica, com busca eletrônica em duas bases de dados de periódicos brasileiros em Psicologia (Pepsic e Scielo). Os parâmetros de inclusão dos artigos foram aqueles com indexadores "corpo" ou "corporeidade", publicados durante a primeira década dos anos de 2000 (publicaçôes entre 2000 e 2009), com texto em português, em revistas científicas da área de Psicologia. Foram excluídos artigos de áreas como Filosofia e Medicina, mesmo quando publicados em revistas de Psicologia.

A categorização foi realizada em duas etapas, a saber: a primeira, de elaboração das categorias, e, a segunda, de categorização do conteúdo dos textos. As categorias foram construídas com base nos objetivos da pesquisa e nos elementos encontrados nos próprios textos. Foram elaborados cinco conjuntos de categorias. (1) Cita ou problematiza: o primeiro grupo analisa se o texto cita "corpo" ou "corporeidade" com base em um constructo teórico já elaborado (apenas cita) ou se elabora ou discute a compreensão de tais termos (problematiza) e teve como objetivo rastrear se o conceito "corpo" ou "corporeidade" tem sido apenas referenciados a partir de teorias/referências já consolidadas ou se encontram-se ainda não sistematizados, necessitando de problematizações e 
novos campos de reflexão e argumentação. (2) Áreas de estudo: essa categoria teve como objetivo investigar as áreas da Psicologia nas quais o tema aparece como interesse de estudo. As subcategorias derivaram das áreas encontradas nos textos, a saber: "educação", "epistemologia", "história da Psicologia", "Psicologia do desenvolvimento", "avaliação psicológica", "Psicologia clínica", "Psicologia da saúde", "psicossomática", "Psicologia do trabalho", "Psicologia social" e "outras". (3) Teorias de base: o objetivo dessa categoria foi mapear as teorias ou abordagens que se dedicam ao estudo do tema. Foram identificadas as seguintes subcategorias: "histórico-cultural", "cognitiva", "psicanálise", "Psicologia fenomenológica", "Psicologia analítica", "teoria das representaçōes sociais", "leituras filosóficas", "outras" e "não há". (4) Metodologia: o quarto grupo de categorias investiga as metodologias utilizadas para o estudo do corpo. As subcategorias encontradas foram: "quantitativa", "qualitativa", "quanti e quali", "estudo teórico" e "revisão de literatura". (5) Concepçôes de corpo: o último conjunto de categorias teve como objetivo analisar e especificar quais foram as definições de corpo utilizadas nos textos. Foram encontradas as seguintes concepçôes de corpo: "sensação/ intuição", "pulsão", "histórico-cultural”, "imagem corporal”, "unidade corpomente", "corpo-sujeito", "corpo-objeto", "estrutura experiencial vivida", "lócus relacional", "efeito de linguagem", "corpo sem órgãos" e "sem definição". Os textos foram divididos entre os pesquisadores que realizavam uma primeira categorização, tal como descrito acima. Em uma segunda etapa, as categorizações eram discutidas grupalmente para eliminar divergências de interpretação especialmente no que diz respeito à quinta categoria, uma vez que as concepções de corpo e corporeidade nem sempre eram explicitamente designadas no corpo do texto e, portanto, eram abstraídas com base em indicadores, tais como teoria utilizada e palavras-chave nas frases de referência que continham a palavra "corpo".

Após a categorização dos artigos e seus conteúdos, foram contabilizadas as frequências de cada categoria e analisadas as relações encontradas entre área e metodologia, área e teoria, concepções de corpo e metodologia, concepções de corpo e teoria e, finalmente, concepções de corpo e área.

\section{Resultados}

Foi encontrado um total de 138 artigos, porém, lidos, analisados e classificados apenas 126, após a aplicação dos critérios de exclusão. Os resultados serão apresentados pelos conjuntos de categorias acima descritos. Nota-se, conforme Figura 1, que o tema apresentou um crescimento relevante no final da primeira década dos anos de 2000, intervalo de nossa análise, com um pico de publicações em 2008 e um pequeno decréscimo em 2009: 
Figura 1. Distribuição da frequência das publicações por ano

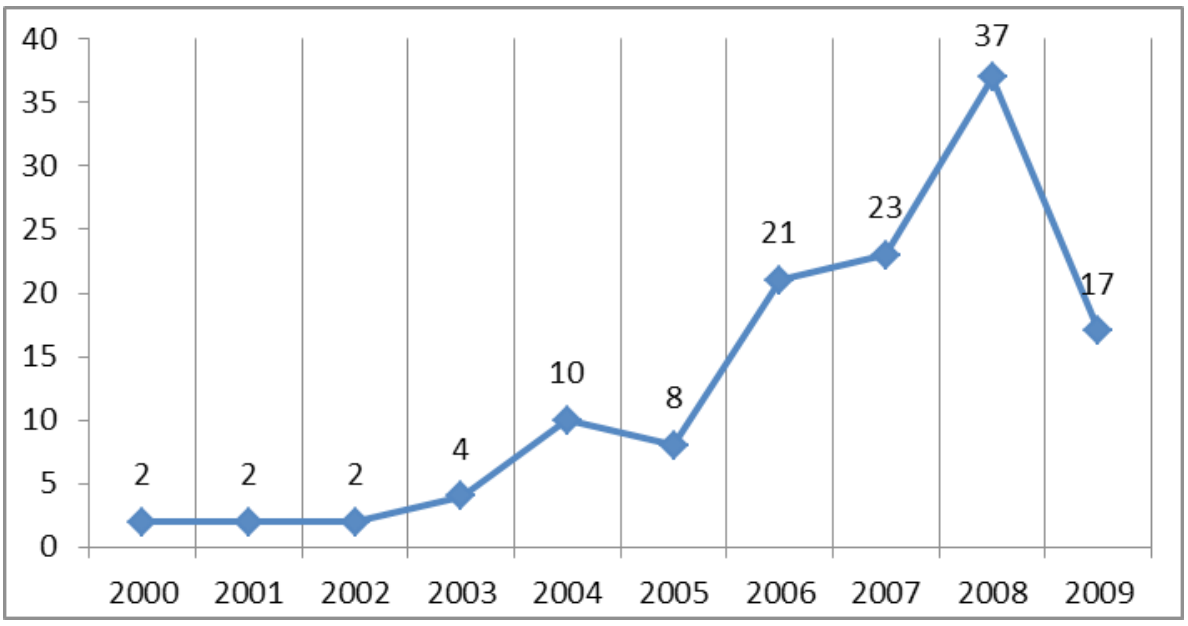

Fonte: Elaborado pelos autores.

Ressaltamos que não foi encontrado nenhum outro dado relevante no que diz respeito à correlação entre as outras categorias e os anos de publicação, tais como tendência de área, teoria ou tipo de conceituação de "corpo" ou "corporeidade".

\section{Cita ou problematiza?}

Não foi encontrada diferença significativa entre a quantidade de artigos que "apenas citam" "corpo" e "corporeidade" $(48,4 \%)$ e aqueles que "problematizam" ou definem tais termos $(51,6 \%)$, seja elaborando uma nova concepção destes, seja abrindo outras perspectivas ou propondo novos conceitos para reflexão dos temas. Não foi analisada uma possível distinção entre as definições de "corpo" e "corporeidade", por não aparecer nenhuma distinção significativa entre os termos na primeira etapa da análise.

Em relação à problematização ou não dos temas em relação às teorias usadas, observou-se que a "psicanálise" e os textos que trabalham com "leituras filosóficas" apresentam maior frequência de textos que "problematizam" o tema $(56,1 \%$ e $54,5 \%$, respectivamente) do que textos que "apenas citam", apresentando uma mesma proporção entre as categorias $(0,8)$. Tal fato se inverte nos textos de referências "histórico-culturais", nos quais há mais artigos citando os termos "corpo" e "corporeidade" $(62,5 \%)$ do que os problematizando $(37,5 \%)$. Paralelamente, observa-se que os dois textos de "Psicologia cognitiva" e o único texto de "Psicologia analítica" não problematizaram o tema. Metade dos 14 trabalhos em "Psicologia fenomenológica" problematiza "corpo" e 
"corporeidade", e a outra metade "apenas cita". O mesmo ocorre com os dois textos que têm como referência a teoria das "representações sociais", não se constituindo como tema significativo para essa área.

Conforme a tabela 1, observa-se que, em se tratando das áreas de atuação, as áreas de "clínica", "educação", "epistemologia" e "psicossomática" apresentam mais textos problematizando os temas do que apenas citando-os. Há uma inversão dessa relação em "Psicologia social" e em "Psicologia da saúde", que apresentam menor número de textos que apenas citam o corpo $(5,6 \%$ e $2,4 \%$, respectivamente). Todos os cinco textos de "história da Psicologia" problematizam, e os únicos textos de "avaliação psicológica" e "Psicologia do trabalho" apenas citam conceitos sobre corpo já estruturados.

Tabela 1. Frequência das categorias "problematizam" e "apenas citam" vs.

área

\begin{tabular}{c|c|c}
\hline Área & Problematiza & Cita \\
\hline Educação & $1,6 \%$ & $0,8 \%$ \\
Epistemologia & $5,6 \%$ & $4,0 \%$ \\
História da Psicologia & $4,0 \%$ & $0,0 \%$ \\
Desenvolvimento & $0,8 \%$ & $1,6 \%$ \\
Avaliação Psicológica & $0,0 \%$ & $0,8 \%$ \\
Clínica & $25,4 \%$ & $20,6 \%$ \\
Saúde & $2,4 \%$ & $4,0 \%$ \\
Psicossomática & $3,2 \%$ & $2,4 \%$ \\
Trabalho & $0,0 \%$ & $0,8 \%$ \\
Social & $5,6 \%$ & $7,1 \%$ \\
Outra & $3,2 \%$ & $6,3 \%$ \\
\hline
\end{tabular}

Fonte: Elaborado pelos autores.

Em se tratando da relação entre "citar" ou "problematizar" e das metodologias utilizadas, nota-se que os "estudos teóricos" e os estudos com "metodologias qualitativas" concentram a maior parte dos artigos, somando $94 \%$ das publicações, com predominância dos "estudos teóricos", com 73\% do total. Metade dos textos "estudos teóricos" problematiza "corpo" e "corporeidade". Apesar de não significativo em termos de frequência, evidencia-se que, nas três "revisões de literatura", o corpo é problematizado. Dos três estudos com metodologia "quantitativa", dois apenas citam e um problematiza e, finalmente, entre os dois que utilizam metodologia "quanti e quali", um "cita" e o outro "problematiza". 
Ainda analisando os artigos em relação à problematização do tema aqui estudado, percebe-se que, ao observarmos as distintas concepçôes sobre corpo, não é encontrado nenhum dado relevante sobre uma tendência à sua problematização ou não.

\section{2 Áreas de estudo}

A área que publica com maior frequência sobre o corpo em Psicologia dentro do universo estudado é a "clínica", com 46\% ( $\mathrm{n}=58)$ das publicações. A essa área se seguem as de "Psicologia social" e "epistemologia", com 12,7\% e 9,5\%, respectivamente. Destaca-se que, curiosamente, as áreas de "Psicologia da saúde" e "psicossomática" representam juntas apenas 11,9\% $(\mathrm{n}=15)$ dos trabalhos, apesar de seus objetos estarem vinculadas a problemas que remetem à temática aqui estudada. As áreas com menor publicação são "educação", "desenvolvimento", "trabalho" e "avaliação psicológica", como se verifica na tabela 2.

Tabela 2. Distribuição da frequência por área

\begin{tabular}{c|c|c}
\hline Área & $\mathbf{f}$ & $\%$ \\
Educação & 3 & 2,4 \\
Epistemologia & 12 & 9,5 \\
História da Psicologia & 5 & 4 \\
Desenvolvimento & 3 & 2,4 \\
Avaliação Psicológica & 1 & 0,8 \\
Outra & 12 & 9,5 \\
Clínica & 58 & 46 \\
Saúde & 8 & 6,3 \\
Psicossomática & 7 & 5,6 \\
Trabalho & 1 & 0,8 \\
Social & 16 & 12,7 \\
Total & 126 & 100 \\
\hline
\end{tabular}

Fonte: elaborado pelos autores. 


\section{Teorias de suporte}

Quando da análise dos textos em relação às teorias, nota-se que a "psicanálise" é a abordagem que aparece como a que mais publica sobre corpo $(65,1 \%)$, tendo sua frequência de publicação maior do que todas as outras áreas juntas. Em segundo lugar, tem-se a "Psicologia fenomenológica", com $11 \%$ dos artigos publicados. Observa-se que as "leituras filosóficas" representam, diante das outras categorias (excetuando-se psicanálise e Psicologia fenomenológica), uma posição de destaque, ocupando a terceira posição. Essa categoria é mais frequente que aquelas que representam perspectivas claramente delimitadas dentro do campo psicológico, como a "Psicologia cognitiva" e a "teoria das "representaçôes sociais", ou mesmo a perspectiva "histórico-cultural", que aparece em quarto lugar, com $6,3 \%$ das publicações.

Figura 2. Distribuição da frequência por teoria

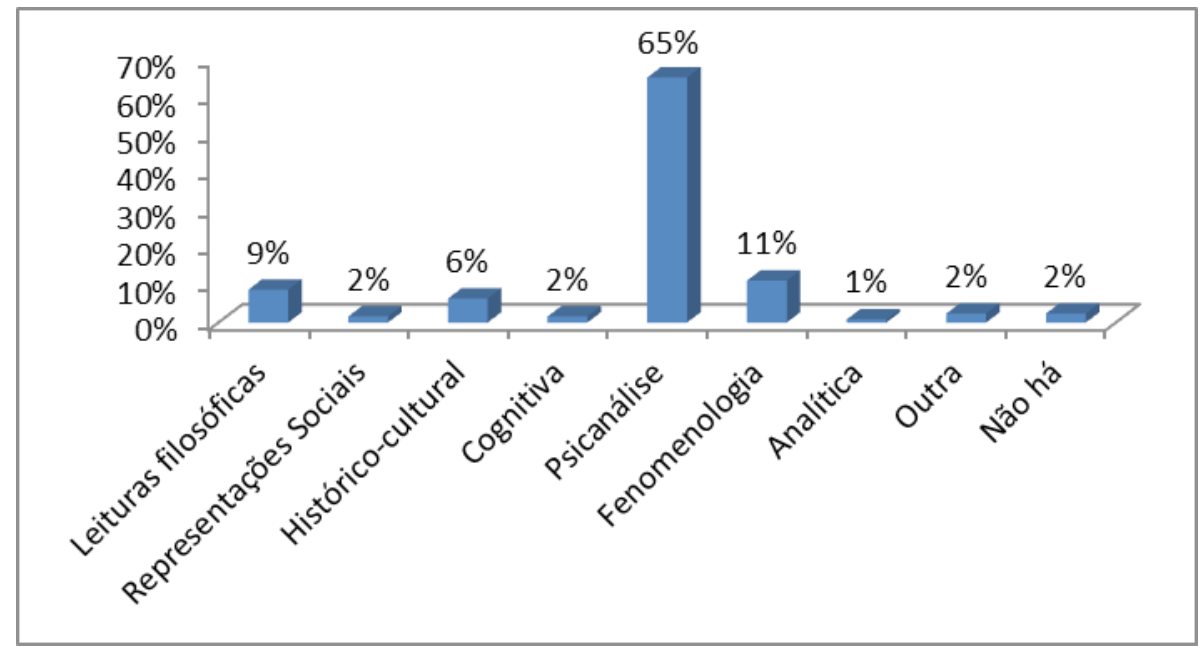

Fonte: elaborado pelos autores.

\section{Metodologias}

No que concerne às categorias metodológicas, os "estudos teóricos" e as "revisões bibliográficas" evidenciam-se como fortemente mais frequentes (75\%), em detrimento dos trabalhos empíricos, sejam eles quantitativos ou qualitativos (25\%). As "pesquisas qualitativas" representam 21\% dos trabalhos, a "revisão de literatura", as "pesquisas quantitativas" e as pesquisas "quanti e quali", $2 \%$ cada. Sublinhamos que não foi encontrada nenhuma relação significativa entre a metodologia e a definição de corpo utilizada. 
Figura 3. Distribuição da frequência por metodologia.

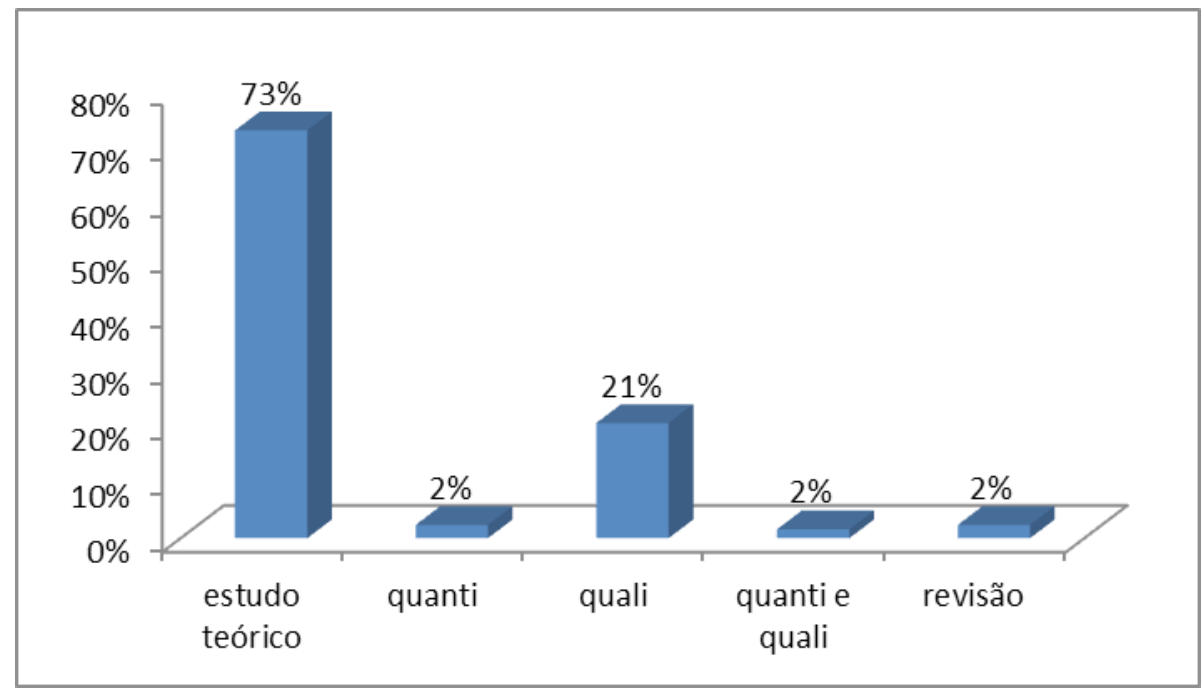

Fonte: elaborado pelos autores.

Relacionando as metodologias às diferentes teorias, observa-se que as abordagens das "representações sociais", "cognitiva" e "analítica" são as únicas que não apresentam estudos teóricos, entretanto a amostra dessas categorias é pequena para qualquer conclusão sobre tal relação. Analisando por teoria, percebe-se que, entre aquelas que apresentam estudos teóricos, há sempre uma predominância destes, com dispersão não uniforme entre as outras metodologias. Os "estudos teóricos" não aparecem como predominante em uma ou outra teoria em particular, contudo é a forma predominante de estudo do corpo em Psicologia, independentemente da teoria, o que nos faz levantar a hipótese de que esse tipo de abordagem ao tema provavelmente se relaciona mais ao próprio tema do que a uma perspectiva teórica.

\section{Concepções de corpo}

Verificou-se que os resultados das análises sobre as concepçôes de corpo encontradas corroboram o resultado anterior de que a "psicanálise" é a abordagem teórica na qual mais se publica sobre a questão, pois a maioria dos artigos concebe corpo como "pulsão" (23,8\%) ou "efeito de linguagem" (18,3\%), conceitos tipicamente psicanalíticos. Para exemplificar corpo como "pulsão", temos Reis (2003), que, com Freud, afirma que o corpo "é o espaço e o intervalo de tempo no qual se marca a presença do outro, através de sensações e percepções, que atuam como motores da organização do eu enquanto projeção de uma superfície corporal" (p. 190). A categoria "efeito de linguagem" pode ser exemplificada pelo texto em que Elias (2007), fazendo reflexões sobre acompanhamento de 
transexuais candidatas à cirurgia de mudança de sexo, explica que "efeito de linguagem" é como "uma estrutura que surge do corpo-organismo e o conduz à lógica simbólica. Desse modo, a constituição do corpo deve ser suposta como um jogo entre algo que conhece e algo que ignora: entre o Eu e o Isso" (p. 125).

Em terceiro lugar, aparece a concepçáo de corpo como "estrutura experiencial vivida" (12,7\%), confirmando a "Psicologia fenomenológica" como a segunda teoria mais utilizada para discutir corpo e corporeidade. As concepções menos utilizadas foram as de corpo como "sensação/intuição" e "corpo-objeto", com uma frequência de 2,4\% em ambas as categorias.

O corpo como "imagem corporal" diz respeito às concepções em que o corpo pode ser entendido como "uma representação interna mental ou um autoesquema da aparência física de uma pessoa" (Gouveia, Santos, Gouveia, Santos \& Pronk, 2008, p. 57). A imagem corporal é um tema clássico nos estudos de Psicologia sobre corpo, mas utilizado apenas em 7,9\% dos estudos, apontando uma tendência para uma proliferação de concepções diversas sobre corpo no campo psicológico. Contudo destacamos que não é possível apontar um "desuso" do conceito de imagem corporal por ter sido ainda muito referenciado no final da década.

A concepção de corpo como "pulsão" é mais frequente em 5 das 12 áreas categorizadas, a saber, "clínica", "psicossomática", "saúde", "Psicologia social" e "educação". Especificamente na área "clínica", o conceito de "pulsão" é tão frequente quanto "efeito de linguagem", evidenciando a psicanálise como teoria relevante na área. Nessa área, também se destacam as ideias de "unidade corpomente" e "estrutura experiencial vivida", típicas da abordagem fenomenológica. Em todas as outras áreas, percebeu-se uma dispersão tal dos conceitos que não foi possível discriminar especificidades sobre como cada abordagem compreende o tema.

Entre os artigos analisados, a Psicologia fenomenológica mostra-se como a teoria com maior unidade conceitual sobre o tema, pois $64,3 \%$ de seus estudos abordam o corpo como "estrutura experiencial vivida", concepção consonante com a perspectiva da abordagem, como aparece em Rosa e Campos (2009): "A expressão do corpo, a expressão das formas corporais, é a expressão de si mesmo" (p. 127-128), ao defenderem que, para o obeso, "o corpo é o pano de fundo conflituoso e expressivo de seus desejos" (p. 130).

Em psicanálise, por outro lado, encontra-se uma enorme diversidade de concepções, apesar de essas se concentrarem em "pulsão" (35,4\%) e "efeito de linguagem" (24,4\%), como citado anteriormente. Como exemplo dessa diversidade, podemos citar o artigo em que Peixoto Júnior (2008), revendo a 
teoria winnicottiana, "para situar o corpo como base para a continuidade do ser" (p. 956), ressalta que Winnicott "talvez tenha sido o psicanalista que mais contribuiu para reverter as pretensões dos desprezadores do corpo no meio psicanalítico" (p. 956). As únicas concepções não usadas pela psicanálise foram corpo como "sensação/intuição" e "corpo sem órgãos".

\section{Discussão}

Diversamente de Scorsolini-Comin e Amorim (2008), que encontraram menor número de artigos com elaboraçôes dos conceitos "corpo" e "corporeidade" em comparação com aqueles que apenas citam conceitos já existentes na literatura, este mapeamento aponta para uma relaçáo proporcional entre artigos que elaboram ou apenas citam o tema. Essa diferença provavelmente deve-se ao fato de que o número de artigos efetivamente analisados pelos autores foi significativamente menor, pois foram incluídos em sua amostra apenas trabalhos que contribuíam para o estudo de processos de desenvolvimento, além de incluir publicações em outras línguas. Os nossos resultados sugerem que a Psicologia tem discutido mais amplamente a temática do corpo do que anteriormente concluído, como pode ser constatado pelo crescimento expressivo das publicaçóes ao longo da década, pois foram incluídos em nossa análise dados de outras áreas que não apenas o desenvolvimento.

Além de os dados apontarem visivelmente um crescimento do interesse pelo tema, observamos que é alta a quantidade de artigos que se preocupam em problematizar e discutir o conceito, fato que remete para a atualidade do tema, além de ser um indicador, assim como demonstrado por ScorsoliniComin e Amorim (2008), de que este ainda não se encontra sedimentado, carecendo de clareza conceitual, o que é, de fato, problema muito comum na Psicologia. Verificou-se uma tendência da Psicologia brasileira em acatar o tema da corporeidade como relevante, assim como vemos nas publicações estrangeiras (Scorsolini-Comin \& Amorim, 2008).

Quando iniciamos uma busca preliminar dos artigos pelo sistema de varredura, abandonado posteriormente, percebemos que quase metade dos que falavam de temas relacionados ao corpo, tais como transexualidade, cirurgia bariátrica ou anorexia, faziam-no sem mencionar, tampouco conceituar, corpo ou corporeidade. Ao mesmo tempo, para nós foi uma surpresa constatar, no nosso corpo de dados, que artigos sobre temas como transexualidade, fibromialgia, anorexia e bulimia, obesidade mórbida, abuso sexual e lesões por esforço repetitivo, entre outros, desprezavam completamente a questão da corporeidade 
ou da relevância do corpo em seus estudos e reflexões. Essa ausência se confirma pela baixa quantidade de publicações em Psicologia da saúde e psicossomática encontradas.

Observa-se que as pesquisas que se utilizam de "metodologias qualitativas" e os "estudos teóricos" são as que apresentam maior possibilidade de discussão dos paradigmas existentes, bem como a problematização dos conceitos, pela sua própria natureza de busca do qualis e do específico em detrimento da frequência ou generalização. Por outro lado, percebe-se que a predominância de estudos teóricos sobre o assunto pode significar uma dificuldade da área em conduzir pesquisas que investiguem o papel do corpo e da corporeidade nos problemas humanos, centrando sua produção em discussão de modelos teóricos, porém, pouco os confrontando empiricamente com dados provenientes de demandas que envolvem o cotidiano de trabalho dos psicólogos. Tal confrontação, quando acontece, dá-se predominantemente pela via qualitativa, tipo de pesquisa que se caracteriza, entre outras coisas, pela compreensão dos processos estudados, por meio da descrição, das significações e da interpretação do pesquisador. Tal valor descritivo e interpretativo poderia ser mais bem explorado no estudo do tema, pois vai ao encontro da predominância de trabalhos clínicos, bem como dos problemas metodológicos e epistemológicos impostos por um objeto de estudo com tal complexidade, estando vinculado a problemas tão distintos quanto transexualidade, anorexia e lesão por esforço repetitivo.

Um dado que chama a atenção diz respeito aos artigos que se utilizam de "leituras filosóficas" com o objetivo de refletir sobre temas psicológicos e que claramente se situam no campo da Psicologia e não da filosofia (Silveira, 2007; Prado Filho \& Trisotto, 2008). Um dos autores mais frequentemente utilizados entre os textos dessa categoria é Michel Foucault (Tassel, 2009; Silveira \& Furlan, 2003). Pela frequência de estudos que necessitam recorrer a outras áreas do conhecimento, tal como a Filosofia, é reforçado o caráter de riqueza e complexidade do objeto aqui estudado, também claramente evocado pela variedade de temas, abordagens de pesquisa e estudo, bem como pela multiplicidade de áreas de atuação que aparecem como interessadas ou próximas à temática da corporeidade. Tais características certamente conduzem a dificuldades teóricas e práticas, com implicaçôes epistemológicas e profissionais.

No que diz respeito à teoria psicanalítica, predominante no estudo da temática, a intrínseca relação entre corpo e pulsão pode explicar o grande número de publicações nessa perspectiva teórica. Percebe-se que o conceito de pulsão e a compreensão lacaniana do inconsciente como linguagem predominam nas referências analisadas. Entretanto, é curioso notar que 35,3\% dos textos reconhecidamente psicanalíticos ultrapassam as definiçôes tidas como "clássicas" 
de corpo em psicanálise, apontando para uma provável dispersão interpretativa dessa teoria, como notamos, por exemplo, em Leite (2006) ou em Peixoto Júnior (2008), anteriormente citado. Nota-se que, apesar de se estruturar como uma teoria eminentemente clínica, a psicanálise exerce influência também nas áreas da "psicossomática" (Nicolau, 2008; Ávila, 2004), da "Psicologia da saúde" (Bento, 2008; Elias, 2006), "Psicologia social" (Flügel, 2008; Fontenelle, 2006) e "Psicologia da educação" (Clerk, 2007; Ramos, 2006).

Outra teoria de destaque nesta pesquisa foi a "Psicologia fenomenológica", que apresenta a concepção de corpo como "estrutura experiencial vivida" na maior parte de seus artigos (Martins, 2009; Barreira \& Massimi, 2008), coerente com a concepção de corpo encontrada em Merleau-Ponty (1994) e já evidenciada como uma referência frequente em Psicologia por Scorsolini-Comin e Amorim (2008). Apesar de corpo e corporeidade serem temas clássicos dessa abordagem, nota-se um baixo número de publicações em relação às publicações em psicanálise.

Os dados mostram que as mais variadas teorias em Psicologia se interessam pela temática do corpo, apontando sua relevância para a área. Tal amplitude diverge das conclusões apresentadas por Goia (2007), que afirma que o tema da corporeidade é inexpressivo no campo psicológico, excetuando-se as terapias corporais. Teorias que, inclusive, não aparecem neste estudo.

Duas perspectivas que se ausentam da discussão da temática nos artigos selecionados são a análise do comportamento e a neuropsicologia. Tendo a primeira o comportamento como seu objeto de estudo, nosso corpus confirma a não tematização do corpo nessa perspectiva por não se caracterizar como um problema entre analistas do comportamento. Em contrapartida, em uma primeira aproximação, poderíamos esperar que o tema fosse abordado pela neuropsicologia. Entretanto nos parece que o corpo não figura como questão para tais psicólogos, no máximo corpo como "cérebro", uma vez que seu aspecto orgânico e biológico é enfatizado em detrimento do que chamamos de mente, consciência ou psiquismo, pois concebe a mente como epifenômeno da produção material do cérebro.

No que diz respeito às conceituações sobre corpo e corporeidade, nota-se que há um pequeno número de artigos que entendem corpo apenas como objeto (Maia, 2008) ou como sujeito separadamente (Sander, 2009) (8\%). Por outro lado, verificamos que os paradigmas presentes nas subcategorias "efeito de linguagem" e "imagem corporal" apontam para uma compreensão do corpo como elemento secundário em relação a outros elementos da totalidade psíquica.

O corpo é reconhecido em $23(69,7 \%)$ desses artigos como integrante da 
totalidade psíquica humana, como pode ser verificado nos exemplos a seguir: quando se destaca a centralidade do corpo e do aspecto relacional (Amorim \& Ferreira, 2008), quando se afirma que "o corpo é fenômeno que funda o humano" (Silva, 2008, p. 29) ou quando se considera que "os sintomas somáticos e psíquicos de uma determinada enfermidade não são de natureza distinta e sim dois lados de uma mesma moeda" (Queiroz, 2008, p. 922). Assim, foram elencados para esse grupo todos os textos que não compreendem "corpo" como um objeto separado da subjetividade, mas sim como participante inalienável dos processos psicológicos, confirmando as conclusões de Scorsolini-Comin e Amorim (2008), de que há uma busca para romper com as dicotomias clássicas encontradas na ciência e divergindo daquelas de Pruzinsky e Cash (2002), que apontam para uma tendência de a Psicologia compreender o corpo em oposição ao psiquismo.

\section{Conclusões}

Esta pesquisa nos evidencia como a temática do corpo vem ocupando um lugar cada vez mais relevante e de destaque nas produções em Psicologia, certamente, respondendo a uma demanda suscitada por problemas práticos. O tema se mostra de interesse de variadas áreas e teorias, não sendo exclusivo de nenhuma perspectiva. É um tema que demanda frequentemente de seus pesquisadores vinculaçôes e diálogos com áreas distintas, mostrando um problema com natureza tal que com frequência exige uma análise multidisciplinar. Contudo a temática ainda se mostra frágil do ponto de vista epistemológico, estando disperso entre paradigmas extremamente diversos e até mesmo contraditórios, por vezes dentro de um mesmo escopo teórico. Outra lacuna percebida é o fato do tema ser pouco estudado do ponto de vista empírico, uma vez que os trabalhos teóricos representam um expressivo total de $73 \%$ da produção, apontando para uma necessidade de a Psicologia não apenas tematizar o problema conceitualmente, mas também compreendê-lo em seus modos de influência ou pertinência a problemas práticos.

Entendemos que uma das principais contribuições trazidas por esta investigação se trata da constatação da coexistência de paradigmas fortemente dissonantes na literatura científica em Psicologia sobre o corpo, por exemplo, os dualistas e aqueles com uma abordagem do sujeito como totalidade corpomente, mesmo dentro de uma mesma abordagem teórica. Diante da pluralidade de discursos sobre corpo em Psicologia na atualidade, esta pesquisa contribui para o mapeamento das diversas formas de se conceber a questão do "corpo" e da "corporeidade" como ferramenta para melhor nos situar em nosso campo. 
De fato, tal pluralidade não se distancia e até mesmo reproduz a pluralidade de compreensões sobre qual seria o objeto de estudo da Psicologia. O que nos parece inquietante é a multiplicidade de concepções dentro de uma mesma perspectiva, o que mereceria novos estudos para uma melhor compreensão do fenômeno. Tais divergências seriam fruto de inconsistências teórico-epistemológicas ou estariam relacionadas à pesquisa? $\mathrm{Ou}$ ainda, estariam simplesmente relacionadas à complexidade do tema e a pluralidade de problemas aos quais está vinculado? Estas não são questôes simples de responder. A quantidade expressiva de trabalhos teóricos e conceituais aqui encontrados, em detrimento dos empíricos, remetenos à necessidade intrínseca das diversas abordagens psicológicas buscarem uma ocupação rigorosa e constante com suas bases metodológicas e epistemológicas. $\mathrm{O}$ que falta para que um tema amplamente discutido teoricamente, relacionado a tantos e tão variados problemas concretos, seja enfim objeto de um maior número de pesquisas empíricas? O risco de nos manter tratando temas de tamanho relevo predominantemente do ponto de vista teórico é produzir um deslizamento teórico-conceitual em que os modelos explicativos sejam confundidos com problemas práticos, aplicados e éticos.

Percebemos que a Psicologia brasileira ainda carece de maior aprofundamento da problemática do corpo bem como de uma melhor elaboração dos termos e definições a ela relacionados, contudo se nota claramente que o caminho já está aberto e começa a ser trilhado por diversos autores, como se constata pelo aumento das publicações na área. Tal problemática se coloca como tema sobre o qual muito ainda há a se pesquisar e fundamentar, ao mesmo tempo em que é evidente o crescente interesse por ele bem como uma grande necessidade de se contemplar o papel do corpo nos fenômenos estudados pela Psicologia. Devido a isso, são necessários estudos futuros que mapeiem um maior número de artigos produzidos em Psicologia no Brasil, a fim de poder traçar um panorama mais abrangente da situação atual. Outro modo de ampliar e compreender melhor a problemática seria incluir nas análises produções outras tais como teses, dissertações e livros.

Com os dados apresentados acreditamos ser de grande contribuição estudos que abranjam publicaçôes em outras línguas bem como a estudos que nos permitam compreender melhor as concepções dos profissionais de Psicologia que se encontram afastados da academia, e que poderão nos fornecer melhores parâmetros sobre o impacto e as implicações de perspectivas tão diferenciadas sobre corpo e corporeidade no trabalho cotidiano em Psicologia. 


\section{Referências}

Amorim, K. \& Ferreira, M. C. R. (2008, abril). Corporeidade, significação e o primeiro ano de vida. Arquivos Brasileiros de Psicologia, 60(1), 67-81. Recuperado a partir de http://www.redalyc.org/pdf/2290/229017544007.pdf

Ávila, L. A. (2004, dezembro). Grupo e corpo, no enfoque do modelo de Cambridge. Vinculo, 1(1), 23-29. Recuperado a partir de http://pepsic.bvsalud. org/scielo.php?script=sci_arttext\&pid=S1806-24902004000100005\&lng=pt $\& \mathrm{nrm}=$ iso\&tlng=pt

Barreira, C. R. A. \& Massimi, M. (2008). O combate subtrativo: a espiritualidade do esvaziamento como norte da filosofia corporal no Karate-Do. Psicologia: Reflexão e Crítica, 21(2), 283-292. Recuperado a partir de http://www.scielo. $\mathrm{br} / \mathrm{pdf} / \mathrm{prc} / \mathrm{v} 21 \mathrm{n} 2 / \mathrm{a} 14 \mathrm{v} 21 \mathrm{n} 2 . \mathrm{pdf}$

Bento, M. (2008). Corpo estranho: narcisismo e desamparo no contexto hospitalar. Revista SBPH, 11(1), 101-111. Recuperado a partir de http://pepsic. bvsalud.org/scielo.php?script=sci_arttext\&pid=S1516-08582008000100008

Clerk, N. (2007). A adolescência e a "metabolização" sonhada do saber. (Viviane Veras, Trad.). Estilos da Clínica, 12(22), 26-47. Recuperado a partir de http:// pepsic.bvsalud.org/pdf/estic/v12n22/v12n22a03.pdf

Elias, V. A. (2006, dezembro). A psicanálise no hospital e a demanda (trans) sexual. Revista SBPH, 9(2), 29-41. Recuperado a partir de http://pepsic. bvsalud.org/pdf/rsbph/v9n2/v9n2a03.pdf

Elias, V. A. (2007). O corpo além do corpo: os reflexos da (im)possibilidade. Epistemo-somática, 4(1), 119-136. Recuperado a partir de http://pepsic. bvsalud.org/pdf/epistemo/v4n1/v4n1a12.pdf

Flügel, J. C. (2008). Sobre o valor afetivo das roupas. Psyche, 12(22), 13-26. Recuperado a partir de http://pepsic.bvsalud.org/scielo.php?pid=S1415$11382008000100002 \&$ script=sci_arttext

Fontenelle, I. (2006). Corpo, mobilidade e a cultura da imagem. Psicologia Hospitalar, 4(1). Recuperado a partir de http://pepsic.bvsalud.org/pdf/ph/ v4n1/v4n1a06.pdf

Goia J. (2007). Memórias de um corpo esquecido. Revista do Departamento de Psicologia - UFF, 19(1), 101-110. Recuperado a partir de http://www.scielo.br/ $\mathrm{pdf} / \mathrm{rdpsi} / \mathrm{v} 19 \mathrm{n} 1 / 08 . \mathrm{pdf}$ 
Gouveia, V. V., Santos, C. A., Gouveia, R. S. V., Santos, W. S. \& Pronk, S. L. (2008). Escala de investimento corporal (BIS): evidências de sua validade fatorial e consistência interna. Avaliação Psicológica, 7(1), 57-66. Recuperado a partir de http://www.vvgouveia.net/sp/images/Gouveia_2008_Escala_de_ Investimento_Corporal_BIS_-_Evidencias_de_sua_validade_fatorial_e_ consistencia_interna.pdf

Le Breton, D. (2012). Individualização do corpo e tecnologias contemporâneas. In E. S. Couto \& S. V. Goellner (Orgs.), O triunfo do corpo: polêmicas contemporâneas (pp. 15-32). Petrópolis: Vozes.

Leite, E. B. P. (2006, dezembro). O corpo do analista: clínica, investigação, imaginação. Jornal de Psicanálise, 39(71), 79-99. Recuperado a partir de http:// pepsic.bvsalud.org/pdf/jp/v39n71/v39n71a06.pdf

Maia, G. F. (2008). Corpo e velhice na contemporaneidade. Estudos e pesquisas em psicologia, 8(3), 704-711. Recuperado a partir de http://www.revispsi.uerj. br/v8n3/artigos/pdf/v8n3a11.pdf

Martins, B. S. (2009, janeiro/abril). O "corpo-sujeito" nas representações culturais da cegueira. Fractal: Revista de Psicologia, 21(1), 5-21. Recuperado a partir de http://www.scielo.br/pdf/fractal/v21n1/02.pdf

Merleau-Ponty, M. (1994). Fenomenologia da percepção. São Paulo: Martins Fontes. [Trabalho original publicado em 1945]

Nicolau, R. F. (2008). A psicossomática e a escrita do real. Revista Mal-Estar e Subjetividade, 8(4), 959-990. Recuperado a partir de http://www.redalyc.org/ pdf/271/27111861006.pdf

Peixoto Junior, C. A. (2008). Sobre a importância do corpo para a continuidade do ser. Revista Mal-Estar e Subjetividade, 8(4), 927-958. Recuperado a partir de http://pepsic.bvsalud.org/pdf/malestar/v8n4/05.pdf

Prado Filho, K. \& Trisotto, S. (2008). O corpo problematizado de uma perspectiva histórico-política. Psicologia em Estudo, 13(1), 115-121. Recuperado a partir de http://www.scielo.br/pdf/pe/v13n1/v13n1a13.pdf

Pruzinsky, T. \& Cash, T. F. (2002). Understanding body images: historical and contemporary perspectives. In T. Pruzinsky \& T. F. Cash (Orgs.), Body image: a handbook of theory, research, and clinical practice (pp. 3-12). New York: Guilford Press. 
Queiroz, E. F. (2008). O inconsciente é psicossomático. Revista Mal-Estar e Subjetividade, 8(4), 911-924. Recuperado a partir de http://pepsic.bvsalud. org/pdf/malestar/v8n4/04.pdf

Ramos, C. (2006, janeiro-junho). O "ressentimento do guerreiro": reflexões sobre corpo e educação a partir do pensamento de Theodor Adorno e da Psicanálise. Interaçôes, 11(21), 9-28. Recuperado a partir de http://pepsic.bvsalud.org/pdf/ inter/v11n21/v11n21a02.pdf

Reis, E. S. (2003). Auto-erotismo: um vazio ativo na clínica contemporânea. Ágora, 6(2), 187-203. Recuperado a partir de http://www.scielo.br/pdf/agora/ v6n2/v6n2a01.pdf

Ribeiro, R. Janine. (2003). Novas fronteiras entre natureza e cultura. In A. Novaes (Org.), O homem-máquina (pp. 15-36). São Paulo: Companhia das Letras.

Rosa, T. V. \& Campos, D. T. F. (2009). Aspectos psicodinâmicos em sujeitos que fizeram a cirurgia bariátrica sem indicação médica. Revista Mal-Estar e Subjetividade, 9(1), 105-133. Recuperado a partir de http://www.redalyc.org/ articulo.oa?id=27113836005

Sander, J. (2009). Corporeidades contemporâneas: do corpo-imagem ao corpodevir. Fractal: Revista de Psicologia, 21(2), 387-407. Recuperado a partir de http://www.scielo.br/pdf/fractal/v21n2/13.pdf

Sant'Anna, D. B. (2004). É possível realizar uma história do corpo? In C. L. Soares (Org.), Corpo e história (pp. 3-12). Campinas: Autores Associados.

Scorsolini-Comin, F. \& Amorim, K. S. (2008, junho). Corporeidade: uma revisão crítica da literatura científica. Psicologia em Revista, 14(1), 189-214. Recuperado a partir de http://www1.pucminas.br/imagedb/documento/ DOC_DSC_NOME_ARQUI20081029093702.pdf

Silva, A. M. (2004). A natureza da Physis humana: indicadores para o estudo da corporeidade. In C. L. Soares (Org.), Corpo e história (pp. 25-41). Campinas: Autores Associados.

Silva, E. R. (2008). As configurações do corpo na cena artística contemporânea. Cogito, 9(9), 29-34. Recuperado a partir de http://pepsic.bvsalud.org/pdf/ cogito/v9/n9a05.pdf 
Silveira, F. de A. (2007, setembro). Corpos invasivos e violentos: subjetivação e incorporação dos sentidos em Foucault e Merleau-Ponty. Revista Mal-Estar e Subjetividade, 7(2), 353-384. Recuperado a partir de http://pepsic.bvsalud. org/pdf/malestar/v7n2/07.pdf

Silveira, F. de A. \& Furlan, R. (2003). Corpo e Alma em Foucault: Postulados para uma Metodologia da Psicologia. Psicologia USP, 14(3), 171-194. Recuperado a partir de http://www.scielo.br/pdf/pusp/v14n3/v14n3a12

Tassel, A. (2009). O corpo e a máquina: um terreno de experiência, a clínica do adolescente. Psicologia Clínica, 21(1), 107-116. Recuperado a partir de http:// www.scielo.br/pdf/pc/v21n1/v21n1a08.pdf

Xavier, C. R. (2008). Diálogo do imponderável: cinco ensaios sobre o objetopsicológico a partir da teoria da mente (Tese de doutorado). Universidade Federal de São Carlos, Centro de Educação e Ciências Humanas, São Carlos. 